\title{
PLC based Multi Three-Phase Induction Motors Motion Controller
}

\author{
Arshed A. Saher \\ Department of Electrical Engineering \\ College of Engineering \\ Basra University
}

\author{
Jawad R. Mahmood \\ Department of Electrical Engineering \\ College of Engineering \\ Basra University
}

\begin{abstract}
Fast advances in digital systems have given designers the possibility of implementing variety of industrial application control functions using Programmable Logic Controller (PLC). This paper presents proposed motion controller for synchronize four 3-ph induction motors based on PLC capability. In general, several control methods are existed to drive the 3-ph induction motor with the aid of Variable Frequency Drive (VFD) under commonly known mode of operation named constant V/F. Master/Slave technique has been adopted in creation of PLC's algorithm because it has an important role that solves the problems behind synchronization of motors such as the sudden changes in speed and load. The serial communications RS485 and digital to analog converter have been used for the purpose of data transmission between the PLC and VFDs. Fuzzy logic controller with two input variables (error and change of error) has been utilized to be part of the complete control system to implement a speed controller for 3-ph induction motor. The proposed system has been tested under different operation conditions and the obtained results proved its validity.
\end{abstract}

\section{General Terms}

Multi three-phase induction motor motion controller

\section{Keywords}

PLC, VFDs, multi-motor simulation, FLC.

\section{INTRODUCTION}

Programmable Logic Controller (PLC) is a special computer used in different educational studies and industrial processes, such as control of machinery on factory assembly lines[1]. One also can say, it is a microcontroller device where the inputs are continuously monitored in digital and analog forms, and controls the actuators (Speed drives, Valves, motorstarters, Solenoids etc.) as outputs according to logic program written by user and stored in a specific memory. This memory could be programmed to store commands or instructions and run functions like, off/on control, counting, timing, arithmetic, data handling and sequencing[2].

The advance of technology and electric drives raises the usage of PLC in automation systems that increase flexibility and reliability of operation and also expand and enhance the production. To get more flexible industrial system, it is needed to use Programmable Logic Controllers interfaced with personal computers, power converters, and other electric devices[3]. Since, the speed and torque of AC motors depend on voltage and frequency that applied to the manipulator sites, Variable Frequency Drive (VFD) are increasingly used to provide flexible method of speed control for industrial applications that require variable speed operation at almost time[3].

A multi-motor system has been used in different industrial applications like industrial robotic arm, production machine, steel mills, conveyer belts and etc. These systems are required in synchronization of speed and angle over acceleration, deceleration, and load changing[4].

There are two ways in the multi motor synchronous operation: mechanical and electrically. Since, the mechanical construction is simple and widely used, but it has a high mechanical wear rate, control accuracy is not high and the range of conduction distance is limited. In electrical motor synchronous control mode is not basically affected by the above conditions, usage is also very flexible[5].

Master/slave strategy are widely used in industrial processes due to its flexibility in solving a challenging problem of synchronizing multi-motor systems that running the motor axes at a definite profile with lowest or zero position error[6]. The overall system must have diverse requirement to achieve these conditions such as driving motors with suitable power value used to run mechanical system, drivers unit uses for the purpose of supplying the power to motors and translate the controller command for each operation state, speed sensor like rotary shaft encoder for each axis which are used to feedback the controller with actual axis state(speed/ position), and main control unit to implement the control algorithm specified to the industrial process under consideration[7].

\section{RESEARCH OBJECTIVES}

The objectives of this research are to:

1. Develop a low cost PLC based multi motor motion controller to replace the expensive ones used in certain application like (Motrona MC700, OmronTrajexa, etc...).The PLC based solution will take care of two targets, the first is to control the speed of the axis motors and the second is to keep the position error between the axes within an allowable band.

2. Construct PLC based fuzzy controller for the purpose of controlling the speeds of 3-ph induction motors.

3. Develop a MATLAB/Simulink model to study the characteristic, response of induction motor and the performance of master slave strategy for multimotor synchronization as theoretical results of the study.

\section{PLC AS MOTION CONTROL SYSTEM}

Previously, the way for synchronizing the axes of multi-motor (Master/slave) system in industrial processes done with a mechanical coupling which, consist of joints like universal cams and gearboxes[7]. In practice, many problems are expected to occur in processes as a result of working conditions like (wearing of joints, protraction of drive chain, etc.) that creates position error in the slave motor with respect to the master. For these causes and others, systems with 
motion control property are needed to offer an accurate synchronization between slave motors and master [5].

In this research, the possibilities of the programmable logic controller are utilized in creating the functionality of the standard multi-motor controllers to synchronize the multimotor system shown in Fig.1.

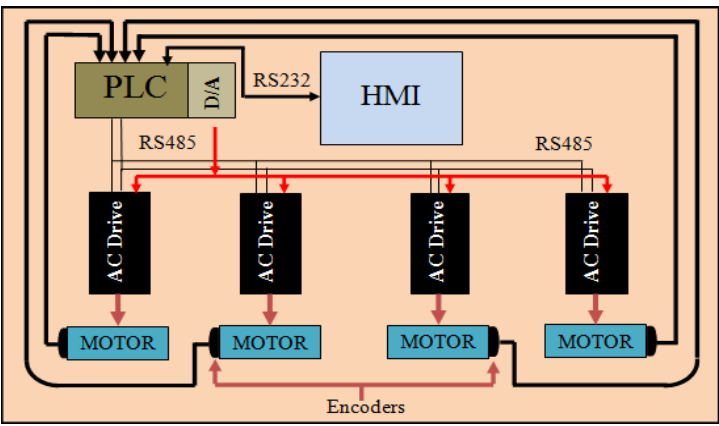

Fig 1: General block diagram of the proposed System

For this system PLC's program has been written to allow each axis to serve as a master or slave depending on the type of selection that entered from the Human Machine Interface (HMI) unit. In general, the proposed system is provided with:

- Analog input/output module labeled (XBF-AH04A) has been used to convert the processed digital data into analog signals from $(0-10 \mathrm{v})$ for driving the $\mathrm{AC}$ drive at specified point.

- Hyundai (N700ESF) AC Drive has been used for feeding the manipulator site of the three phase induction motor with appropriate voltage and frequency under condition of constant V/f ratio.

- XP 30TTE LS touch panel has been used to interface and monitor the status of the system components (PLC, VFD, etc).

- Rotary shaft encoder (E50SF-500-3-T-24) used to supply the PLC with feedback signals in form of pulses that describe the states of the motor speed. This device provides 500 pulses per one revolution on it's A and B channels and provide an index signal per revolution through its $\mathrm{Z}$ channel.

\section{FUZZY BASED MULTI 3-PH INDUCTION MOTORS SPEED CONTROLLER}

Close loop control system is essential for all applications where constant operation is importance. In this study, it has been established with smart controller of superior algorithm to enhance the output quantities (voltage and frequency) of inverter at all-time of working condition and drives the motor with the same reference speed. Fuzzy Logic Controller (FLC) is one of the most intelligent controllers that used for controlling the complex systems due to possibility of covering the wide range of states in a particular operating environment as well as, further robustness and more tolerance to disturbance and noise than other controllers [9]. In this research, it has been utilized with two input variables (speed error and change of error) for controlling the motor speed based on sugeno-style method. Fig.2 defines a matlab/Simulink construction of the fuzzy logic controller where, the two input variables are scaled by value of 0.5 and limited within a range of $(+1,-1)$.

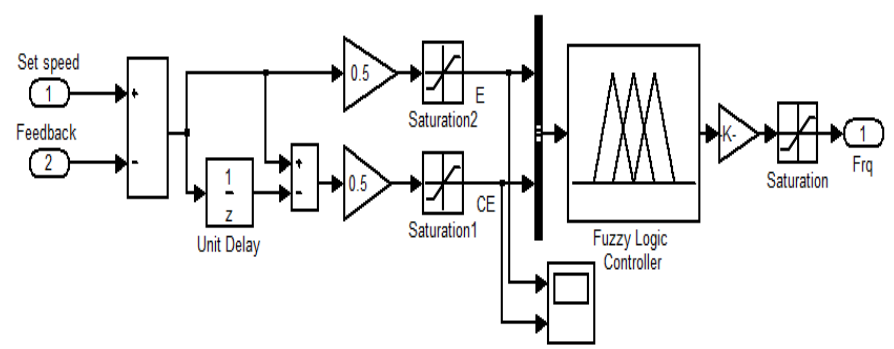

Fig 2: Matlab Simulink of fuzzy controller

The input variables (error and change of error) are fuzzified by a two identical membership functions as specified in Fig.3

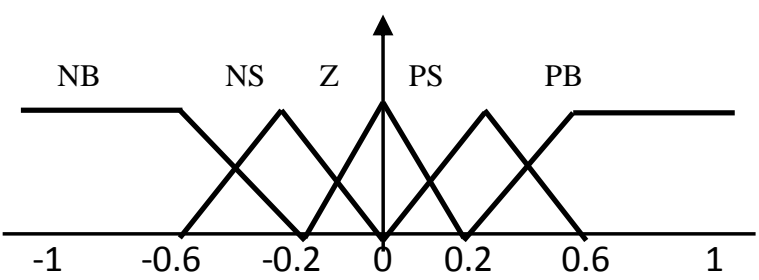

Fig 3: The structure of (e, ce) membership functions

Each input membership function has been described by five linguistic terms specified in Table-1 however, the linguistic terms of the output have been a signed with values of $(\mathrm{NM}=$ $1, \mathrm{NS}=-0.5, \mathrm{Z}=0, \mathrm{PS}=0.5$ and $\mathrm{PM}=1$ )

Table-1 Inputs and output linguistic terms symbol

\begin{tabular}{|c|c|}
\hline Linguistic terms & Symbol \\
\hline Positive medium & PM \\
\hline Positive small & PS \\
\hline Zero & $\mathrm{Z}$ \\
\hline Negative small & $\mathrm{NS}$ \\
\hline Negative medium & $\mathrm{NM}$ \\
\hline
\end{tabular}

Twenty-fife fuzzy control rules are constructed based on input membership functions to perform the control decisions of the output values as shown in Table- 2 .

Table-2 Rule base.

\begin{tabular}{|c|l|l|l|c|c|}
\hline Ce & NM & NS & Z & PS & PM \\
\hline NM & NM & NM & NM & NS & Z \\
\hline NS & NM & NM & NS & Z & PS \\
\hline Z & NM & NS & Z & PS & PM \\
\hline PS & NS & Z & PS & PM & PM \\
\hline PM & Z & PS & PM & PM & PM \\
\hline
\end{tabular}

Each fuzzy rule is expressed by a format of mathematical function (IF-Then) as written below [8]:

$$
\text { IF e is } x \text { AND ce is } y \text { THEN } \boldsymbol{u}=f(e, c e)
$$

where; e, ce are the error and change of error while, $\boldsymbol{u}$ is the output variable with mathematical function of $f(e, c e)$. $x$ and $y$ are fuzzy sets of $e$ and $c e$, respectively. The final output of controller is obtained with respect to sugeno formula [9]:

$$
\text { Output }=\frac{\sum_{j=1}^{c} \boldsymbol{u} j * \boldsymbol{w j}}{\sum_{j=1}^{c} \boldsymbol{w} j}
$$


where; $\mathrm{j}$ is the rule number, $\boldsymbol{u} j$ is the output vector of each rule, and $\boldsymbol{w} j$ is the rule weight that obtained as:

$$
\boldsymbol{w} \boldsymbol{c}=\text { AndMethod }(g 1(\mathrm{e}), g 2(\mathrm{ce}))
$$

where; $g 1,2$ (e.ce) are the error and change of error membership functions, respectively.

\section{SIMULATION RESULTS}

Master-slave control strategy has been utilized in synchronization of four three-phase induction motors. The simulation has been accomplished based on Matlab/Simulink software with only one motor operate as master while, the others are slaves as illustrated in Fig.4.

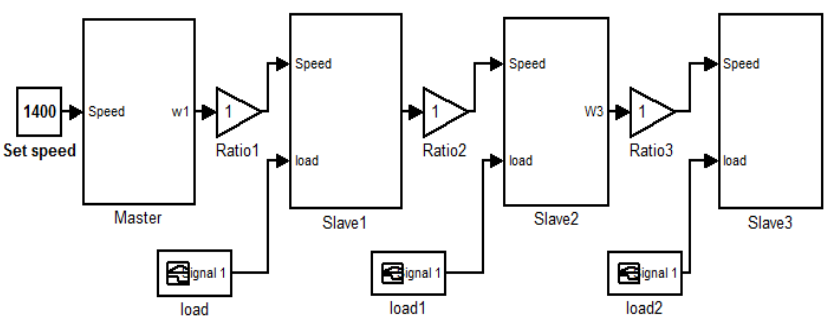

Fig 4: Simulink model of the four motors system

The function block of the master and slaves motors specified in Fig.4 is constructed based on SPWM inverter with constant V/f ratio controlled by an intelligent fuzzy controller as shown in Fig.5.

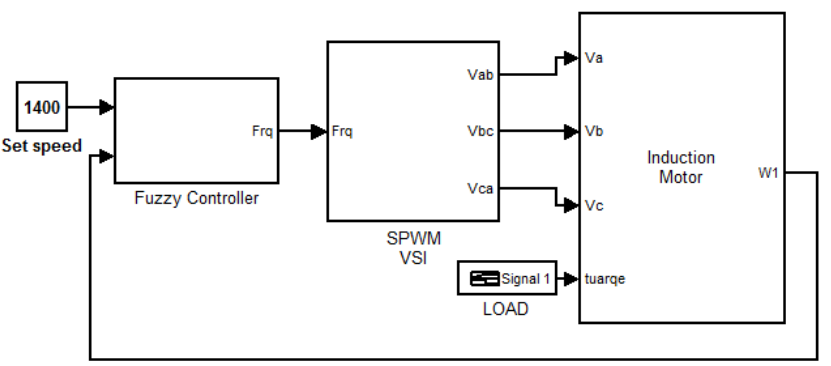

Fig 5: Matlab Simulink model of 3-ph induction motor with close loop system

Different types of tests have been performed to study the response of motors with fuzzy controller.

Fig.6 shows the output voltages of the designed SPWM inverter when $\mathrm{f}=50 \mathrm{~Hz}, \mathrm{DC}$ link voltage of $312 \mathrm{~V}$ and a sinusoidal voltage of $220 \mathrm{~V}$ r.m.s line voltage feed to the 3-ph motor.

Fig.7 illustrates the rotor speed of motor at set value of (1400 r.p.m). From this response it can be noted that, the motor reached the desired speed with raise time of $(0.6 \mathrm{sec})$ and negligible overshot. Fig. 8 shows the speed response of motor at multi speed values $(600,1000$ and 1400 r.p.m). It can be seen that the motor requires a time of $(0.4 \mathrm{sec})$ to change its speed with each changing state. Fig.9 shows the developed torque and characteristics of the induction motor at no-load and at different speed values (600, 1000 and 1400 r.p.m).

In Fig.10 a load of (1.5 Nm) has been applied on the machine with no controller for about $(1.5 \mathrm{sec})$. It can be seen that the motor speed falls down from the desired value and return back when the load is removed. The load is applied to the machine during the time interval $(1.5$ to $3 \mathrm{sec})$. Fig. 11 shows the unloaded speed response of induction motor based on fuzzy controller. It can be seen that the motor reached the desired speed at raise time of $(0.42 \mathrm{sec})$ with neglectable overshoot and settling time. Fig.12 illustrations rotor speed of the induction motor with fuzzy controller, when applied (1.5 N.m) at $\mathrm{t}=(1.5 \mathrm{sec})$ and removed at $(3 \mathrm{sec})$, which shows that fuzzy controller produce very good dynamic and static performance. Fig.13 shows the torque-speed characteristics of motor with fuzzy controller. It can be note that the characteristic of motor has minimum or neglected variation when the motor reached the desired speed. Fig.14 shows the speed response of two motors one as master and the other as slave based on fuzzy controller. It can be understood that master motor and slave motor get the desired speed at $(0.44$ $\mathrm{sec})$ and at $(0.45 \mathrm{sec})$ respectively with neglectable overshoot and settling time. Fig.15 shows the speed response of master/slave motors when the speed ratio is 0.5 . It can be noted that fuzzy controller provide good response and the motors reached the reference speeds with neglectable delay between them. Fig.16 shows fuzzy based speed control of four three-phase induction motors. From this figure, it is clear that the master and slaves reach the desired speed since the slave motors track the speed of the master motor with short delay $(0.01 \mathrm{sec})$.

Fig.17 shows the master and slaves speed response with fuzzy controller by changing the reference speed from (600 to 1000 and then to 1400 r.p.m). It can be noted that the fuzzy controller has very good dynamic and static availability in controlling the speed of motors.

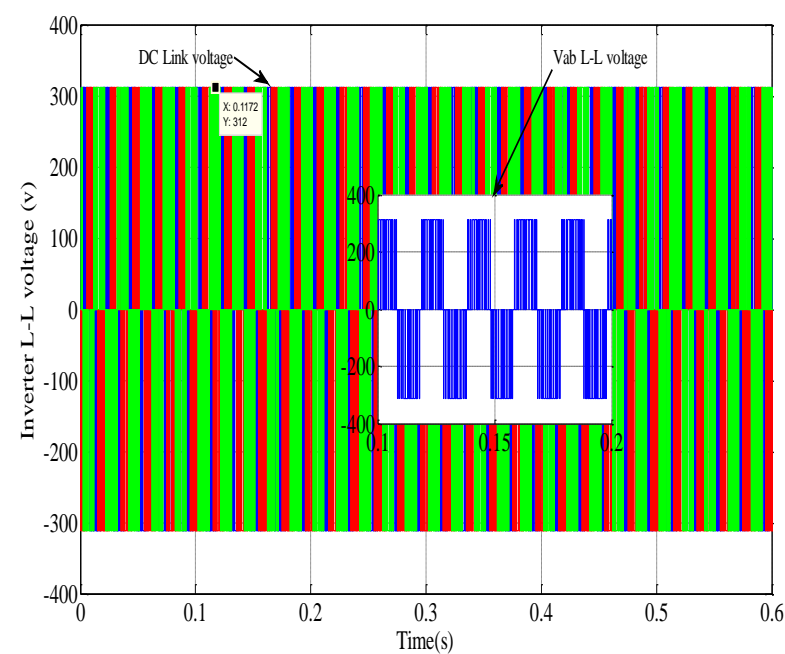

Fig 6: The output voltage of an inverter.

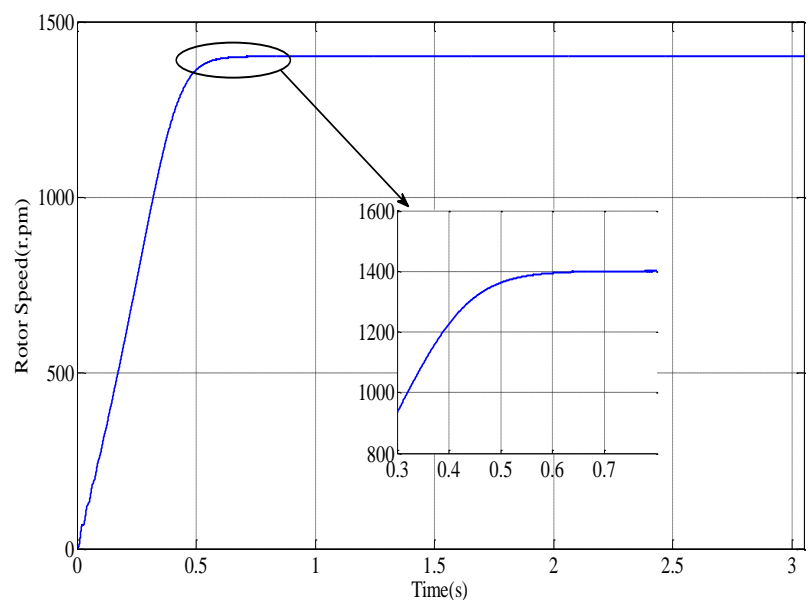

Fig 7: Rotor speed of induction motor in open loop system. 


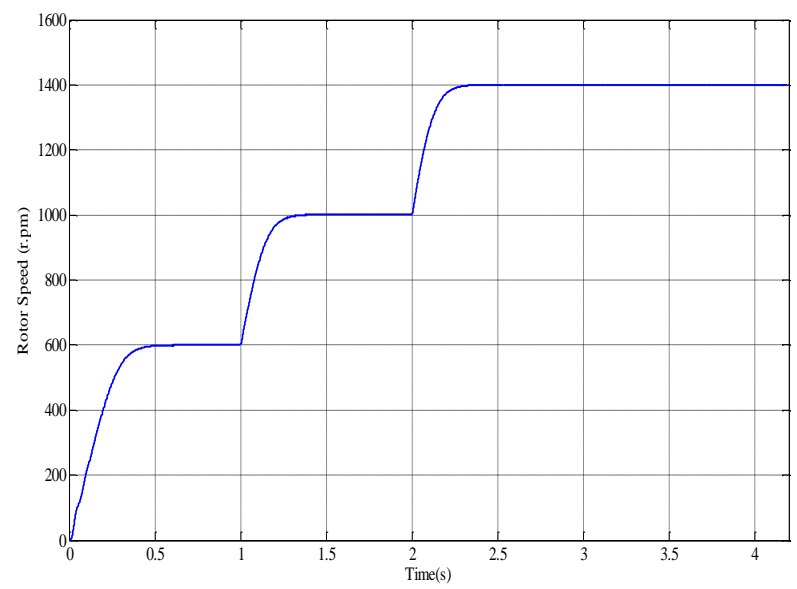

Fig 8: Speed response of uncontrolled induction motor at different set values.

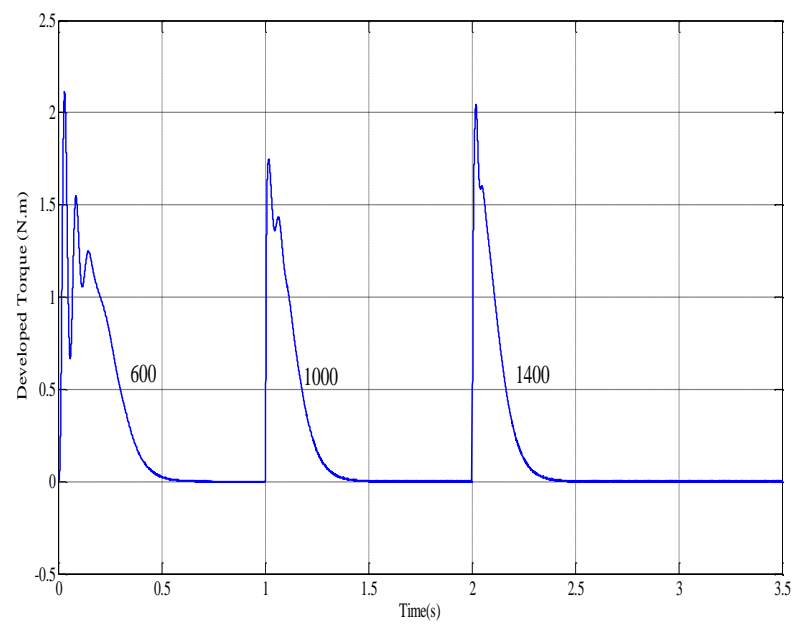

Fig 9: Torque performance of induction motor at different set values.

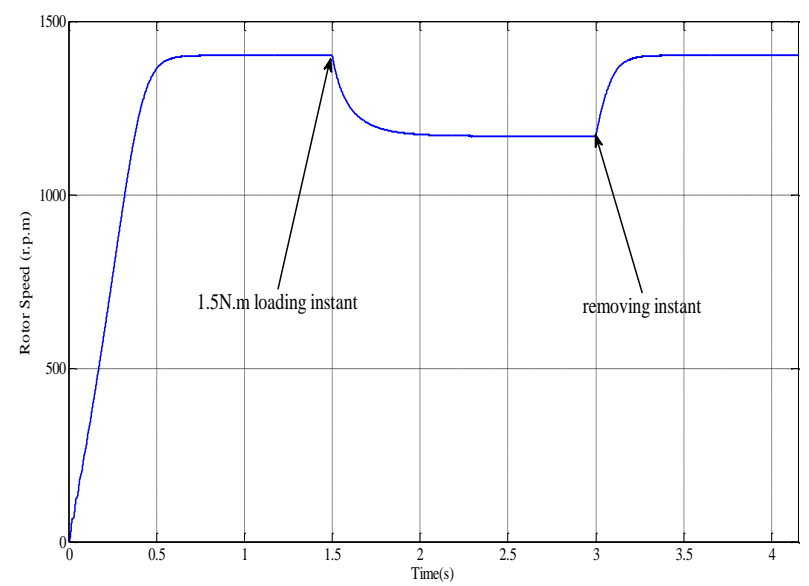

Fig 10: Speed of motor with no control during 1.5 Nm loads.

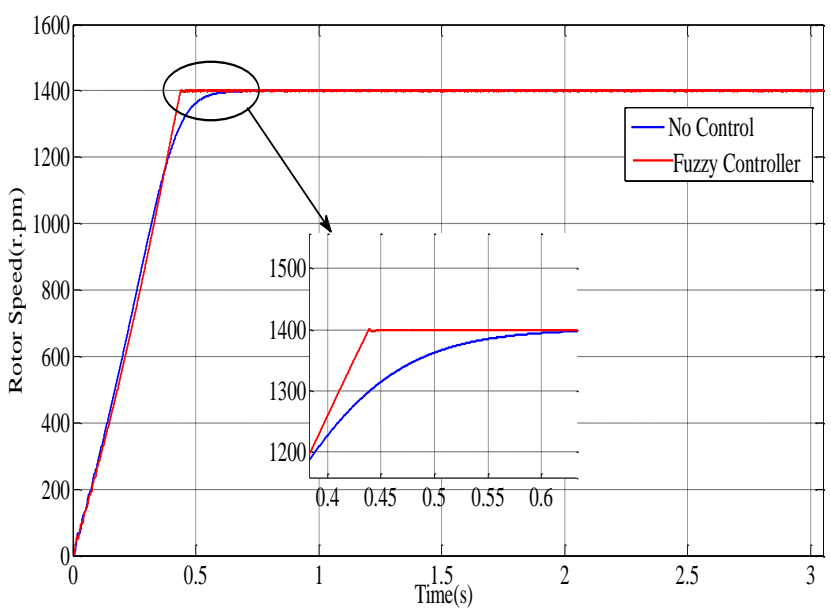

Fig 11: Speed performance of induction motor with fuzzy controller.

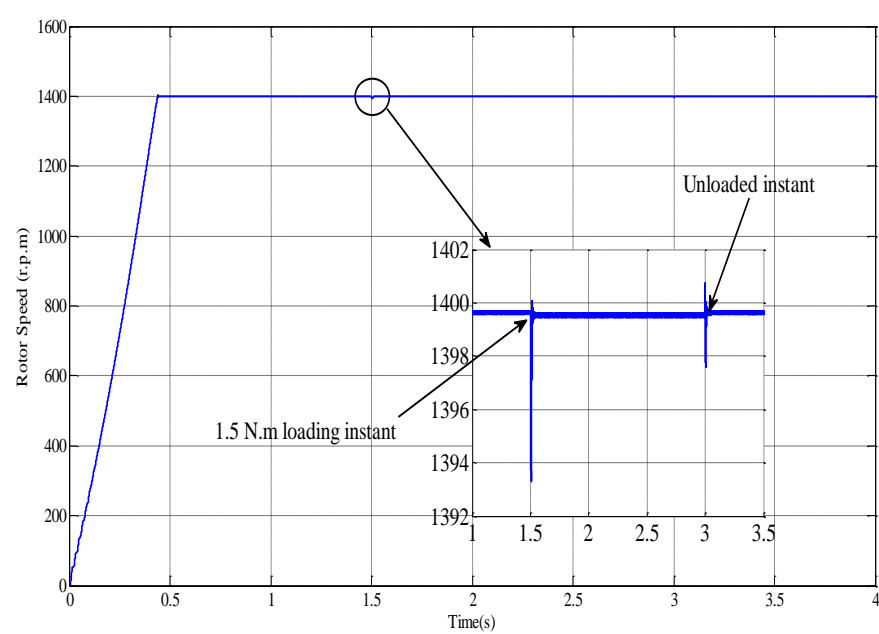

Fig 12: Rotor speed of motor with fuzzy controller at applied $1.5 \mathrm{Nm}$ load.

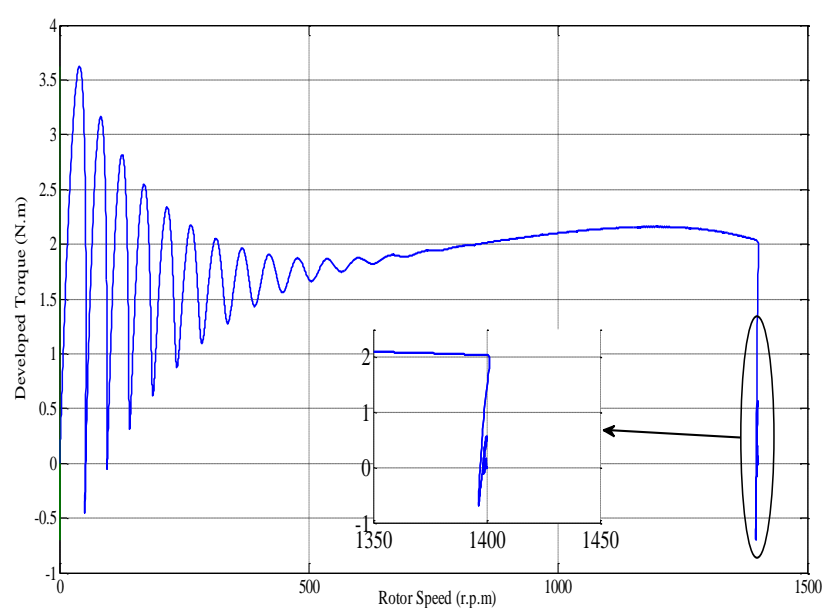

Fig 13: Torque-Speed performance of induction motor based on fuzzy controller. 


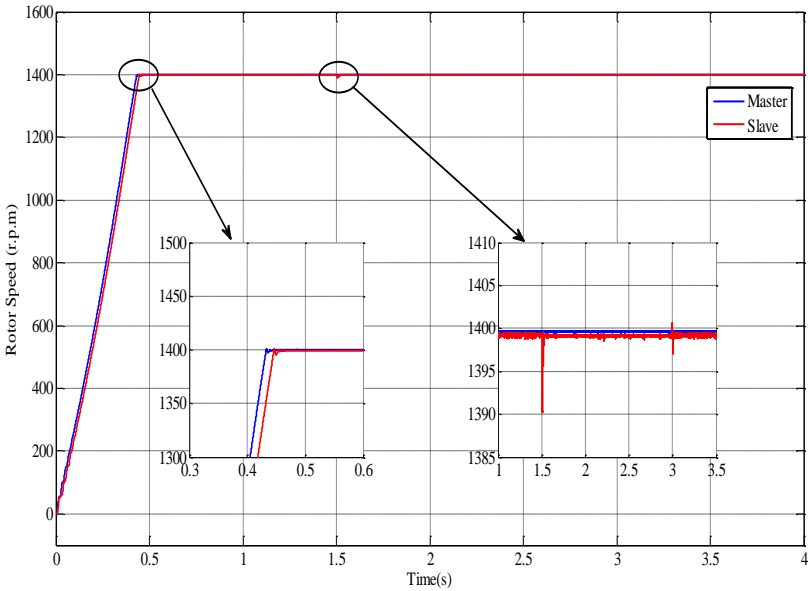

Fig 14: Rotor speed of master/slave motors at applied load of 1.5 to the slave motor with fuzzy controller.

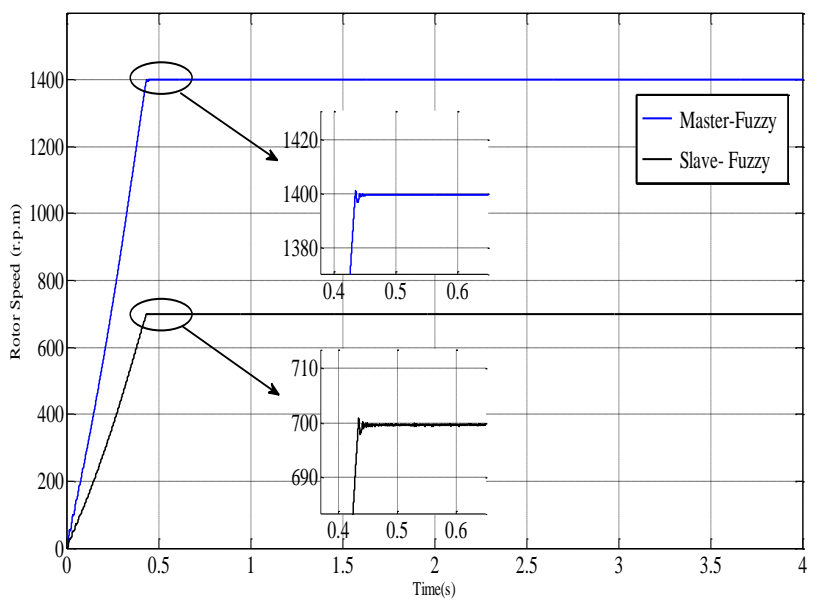

Fig 15: Speed of multi master/slave motor at 0.5 speed ratio.

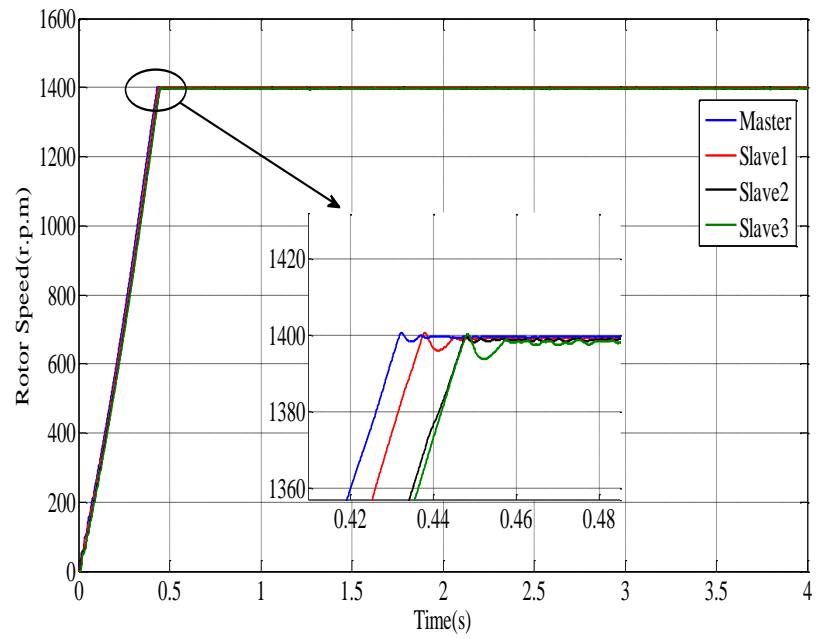

Fig 16: Rotor speed of multi motor master/slaves with fuzzy controller.

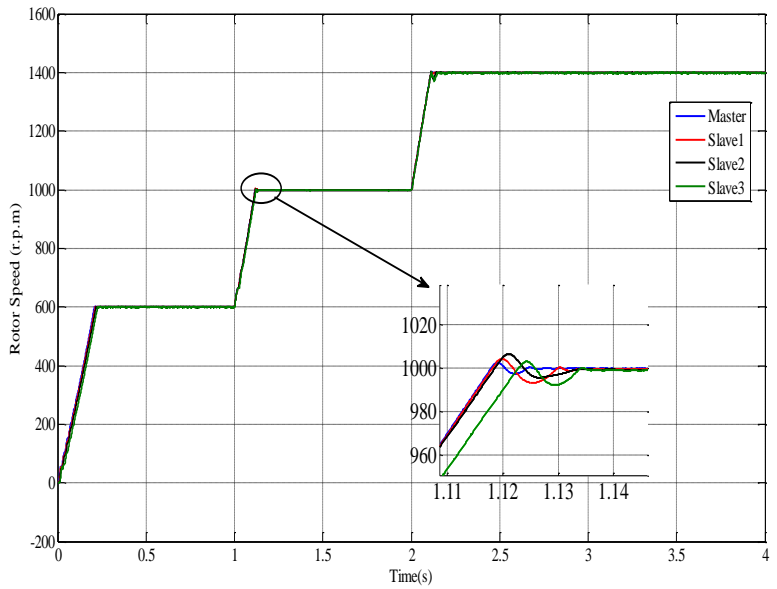

Fig 17: Speed of multi moots master/slaves at different set value with fuzzy controller

\section{IMPLEMENTATION OF THE PROPOSED SYSTEM}

In this system (Fig.18), the PLC has been programmed to play the role of the motion controller in controlling the motion of master/slave motors.

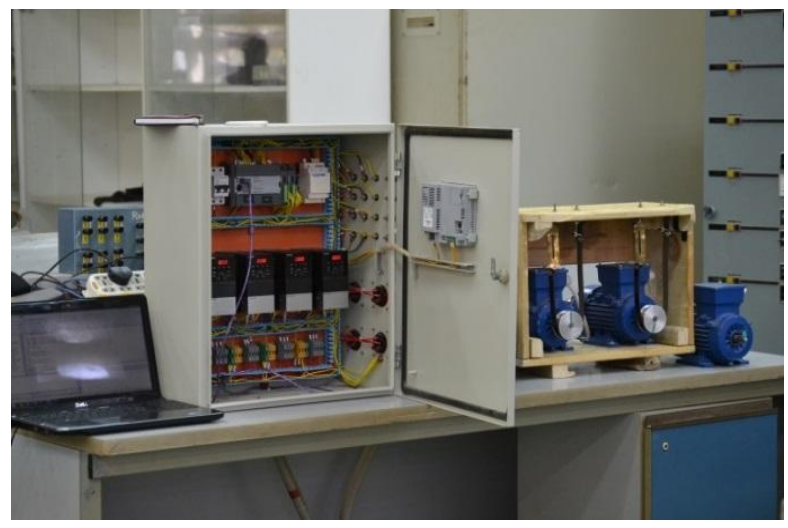

Fig 18: Experimental setup of the proposed system.

The overall integrated system has been implemented in laboratory via construct the control panel with input/output terminal pins, and programming the brain unit (PLC), HMI and all other components. PLC's program has been written according to master/slave strategy. The adopted software utility is illustrated in Fig.19 (for two motor as in illustrated).

Setting the master motor reference speed and speed ratio of each slave motor from the HMI screen will allow the PLC to supply the AC drives with analog signals from $(0-10 \mathrm{v})$ and running the system axes at specified point.

Feedback pulses which delivered to specialized inputs of PLC from each shaft encoders has two important functionality firstly, to control the master motor speed as a control loop whereas the second to set the slave motor speed with required value under Master/Slave strategy.

In case of position control, the $\mathrm{Z}$ channels of master and slave encoders have been arranged to ensure that they are located on a straighter line. The programmable logic controller depends on this incoming signal in measuring the time difference (position angle) between motors axis with respect to reference point and also to decide the type of displacement in case of lead or lag and then reduce the angle difference 
between the motors shaft to acceptable error and under different operating condition.

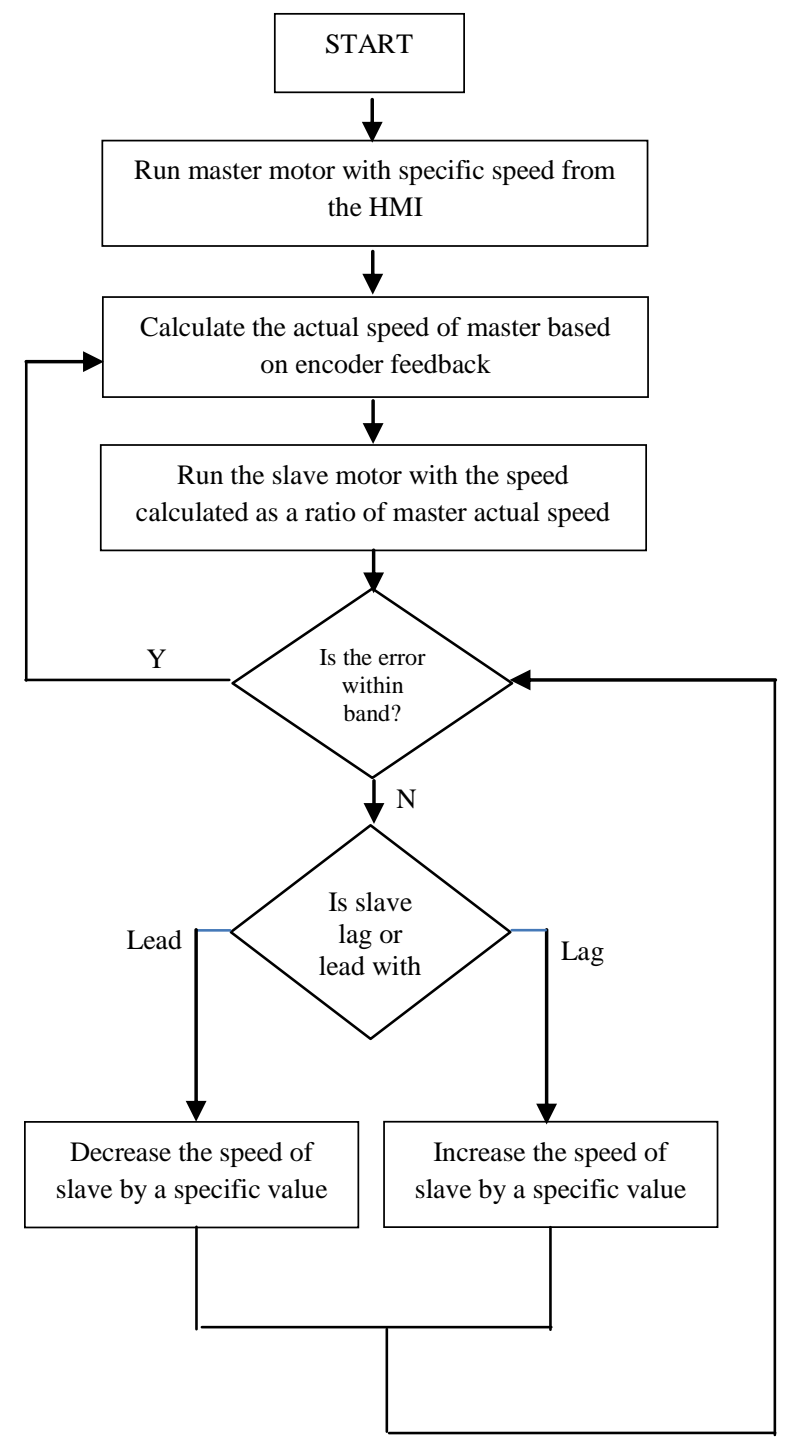

Fig 19: PLC's program flowchart

\section{EXPERIMENTAL RESULTS}

To expose the accuracy range of the proposed system and controller capabilities in synchronization of multi-motor operation, several practical tests have been performed under different working conditions.

Speed response of induction motor has been studied in open loop system as shown in Fig.20. It can be seen that the motor reach the desired speed (1400 r.p.m) at $(1.2 \mathrm{sec})$ while its speed falls down at the instant of applying a sudden load and return back when removed.

Fig.21 shows the motor speed response in open loop (uncontrolled) system and close loop (controlled) system when fuzzy controller is utilized to improve the motor performance during starting and load condition. From this, it can be noted that the study state error parameter quite to (16 r.p.m) with no control but has lowest or zero value with fuzzy controller.

Fig.22 shows the rotor speed response of motor with fuzzy controller when applied load at (1400 r.p.m). It can be seen that the motor reach the reference speed at $0.7 \mathrm{sec}$ with overshoot of (4 r.p.m). Also, the controller requires a time of $0.3 \mathrm{sec}$ to return back to the desired value when applying a sudden load.

Fig.23 show the unloaded speed response of motor with fuzzy controller when the reference speed is taken with three different operating speeds $(600,1000$ and 1400 r.p.m). From the response it can be noted that the controller requires a time of $(0.9$ to $1 \mathrm{sec})$ for each changing state.

Fig.24 shows the speed response master/slave motor based on fuzzy controller. It's clear the motors move together to reach the final speed with a raising time of $(0.7 \mathrm{sec})$ for master motor and $(1.2 \mathrm{sec})$ for slave motor. Also the slave motor requires a time of $1 \mathrm{sec}$ to return back to the speed of the master when applying sudden load.

Fig.25 shows the speed response under master/slaves mode of operation. From this response, it is clear the slave's motors have very good tracking to the task path of master motor. So, if a disturbance has been made by applying and removed a mechanical load on the slave- 1 the follower motors (slave-2 and slave-3) show good tracking to states of leader motor (slave-1) and require a time of $0.9 \mathrm{sec}$ to return back to the reference speed whereas the master does not affected by the disturbance of follower motors

Fig.26 shows the speed response of master/slave motors with fuzzy controller when the speed ratio is 0.5 . It can be noted that the slave motor requires a time of $(0.5 \mathrm{sec})$ to reach the reference speed.

Fig.27 shows the speed response of four induction motors at different set value with fuzzy controller. It is clear that all the motors move together to reach the desired and require a time of $(2 \mathrm{sec})$ with each changing state.

Fig.28 shows the error correction (position error) which expressed in term of time difference between master and slave motor at (300r.p.m) when a sudden load applied at the slave motor. It is clear the slave motor loss its position when applying the load and requires a time of $(5$ to $6 \mathrm{sec})$ to return back within acceptable value.

Fig.29 shows the error correction in term of time difference for the master/slave motor when changing the speed reference of master motor from ( 250 to 450 r.pm) and return back to (300 r.p.m). It can be noted that the proposed compensation mechanism look to be good since it require a time about (5 to $6 \mathrm{sec}$ ) to ensure the error within the accepted values.

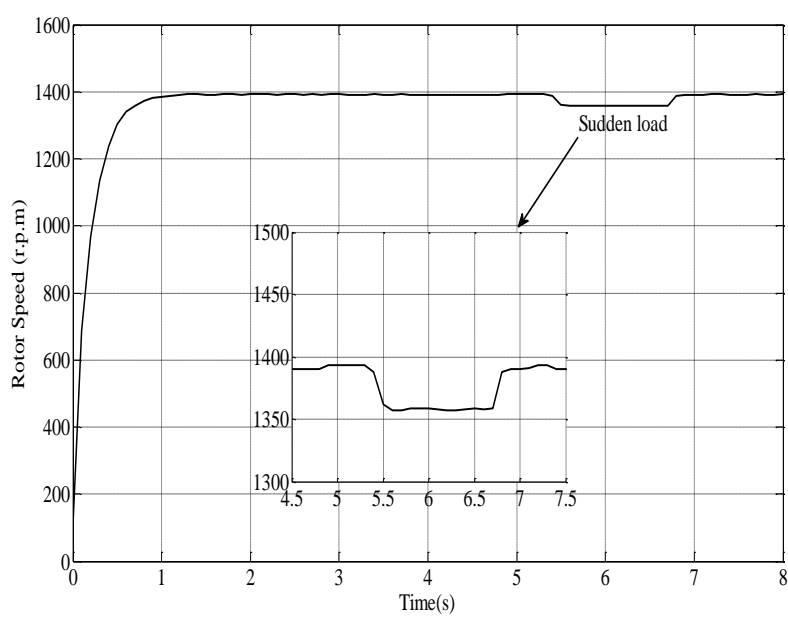

Fig 20: Rotor speed of induction motor when applying a sudden load without controller 


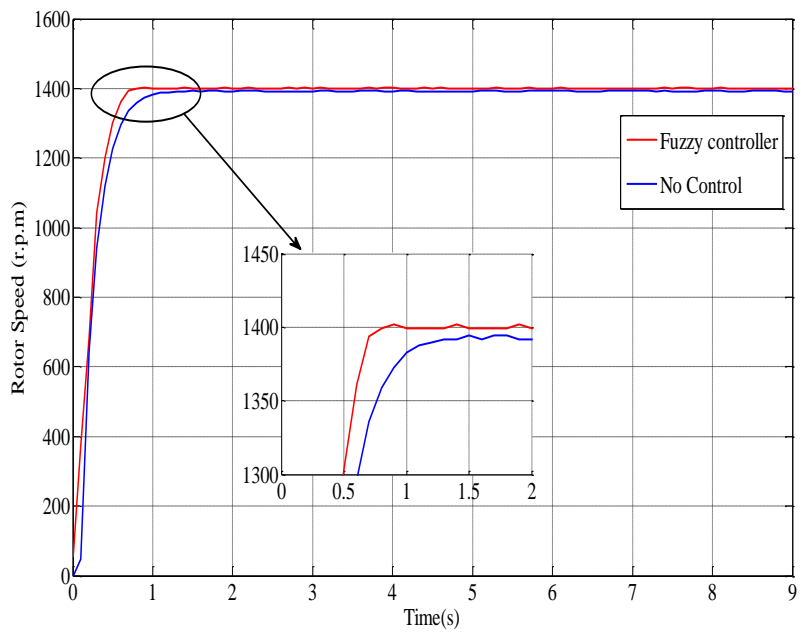

Fig 21: Speed response of unloaded motor when controlled with fuzzy controller

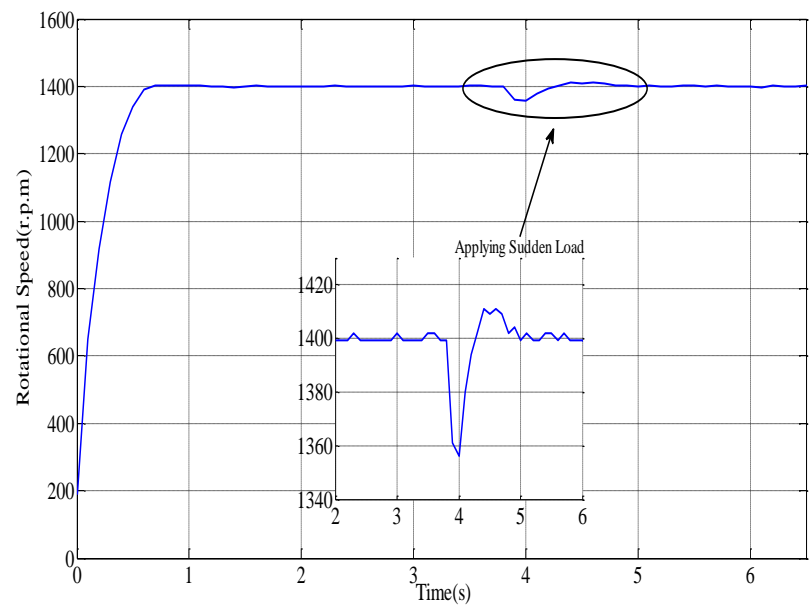

Fig 22: Speed response of loaded motor with fuzzy controller

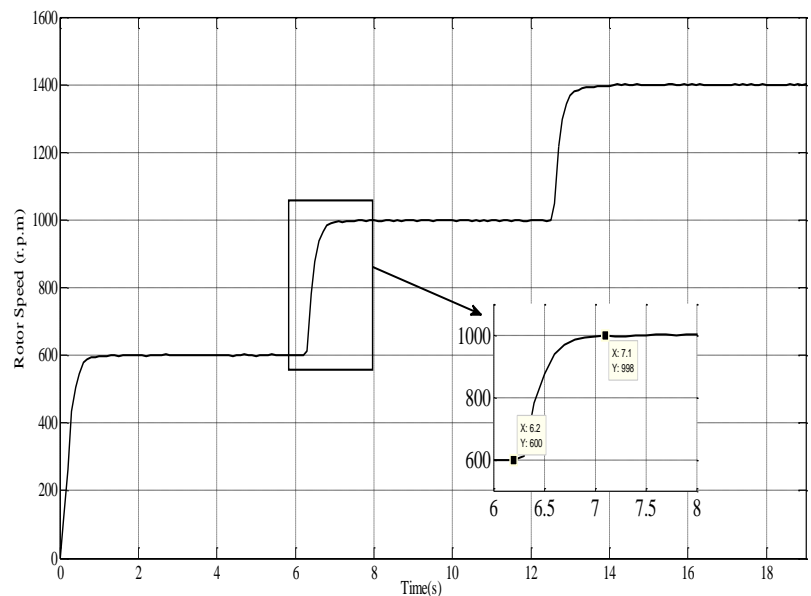

Fig 23: Speed response of induction motor at different speed values with fuzzy controller

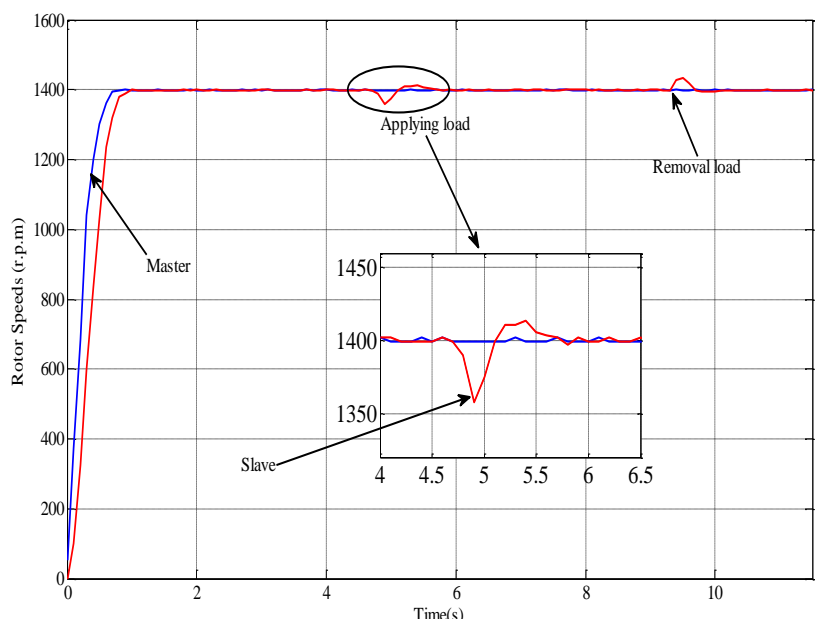

Fig 24: Rotor speed of master/slave motor at applying a sudden load with fuzzy controller

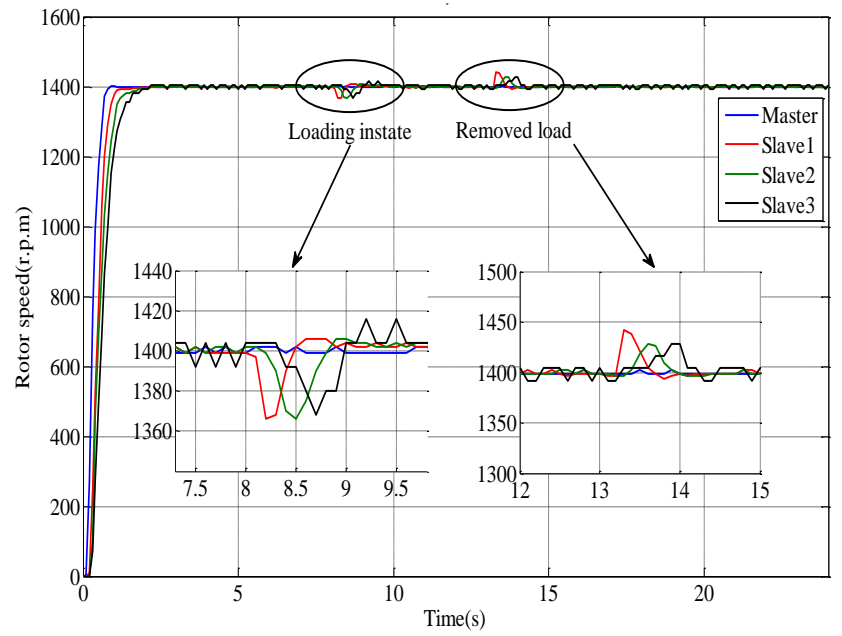

Fig 25: Rotor speed of master/slaves motors at applying a sudden load on slave-1with fuzzy controller.

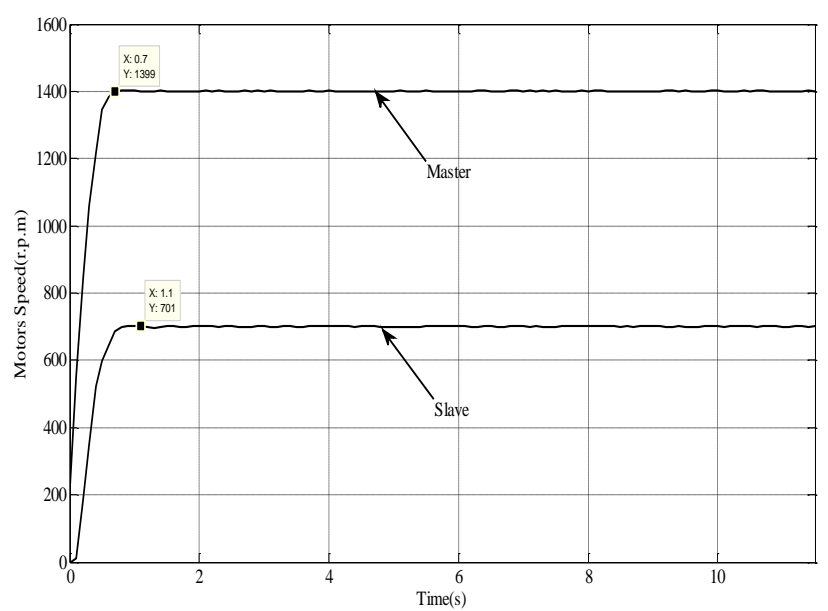

Fig 26: Speed of Master/Slave motors with Fuzzy controller and 0.5 speed ratio 


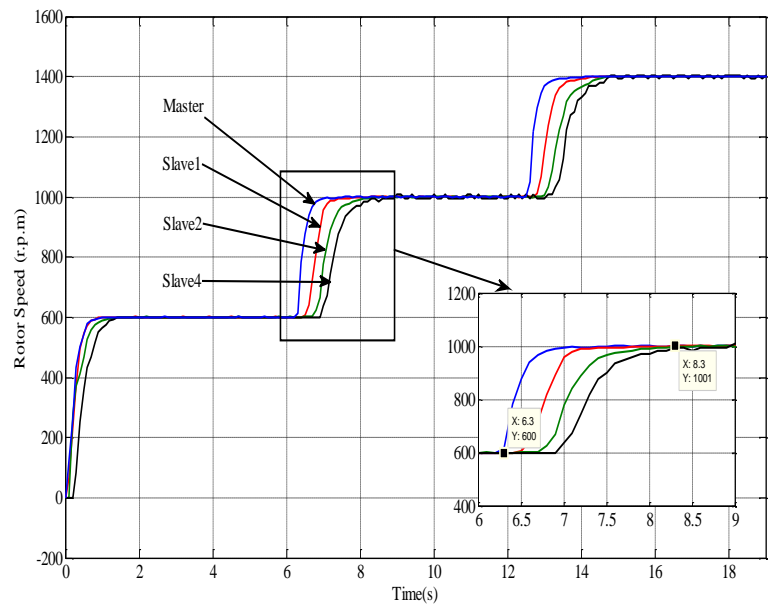

Fig 27: Series arrangements of master/slaves speed response with Fuzzy controller at different set value

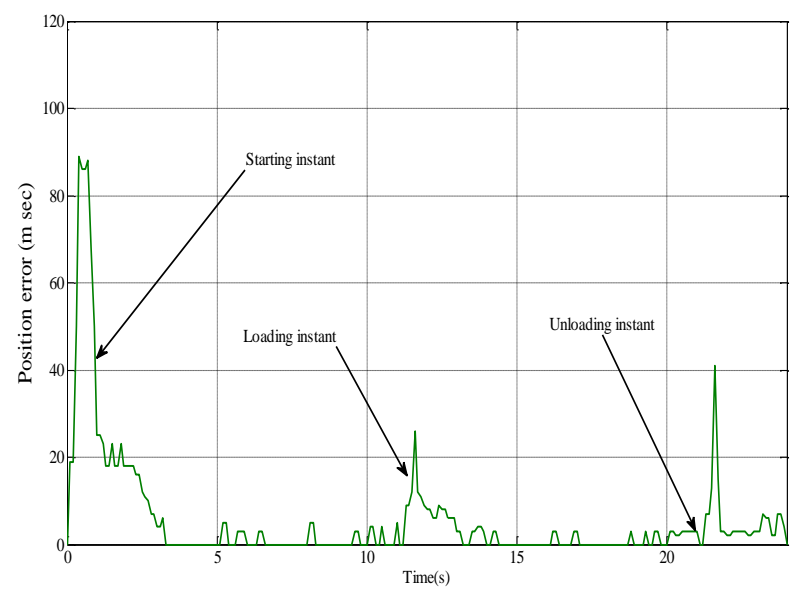

Fig 28: The error angle of master/slave motors at applying and removed a sudden load on slave motor

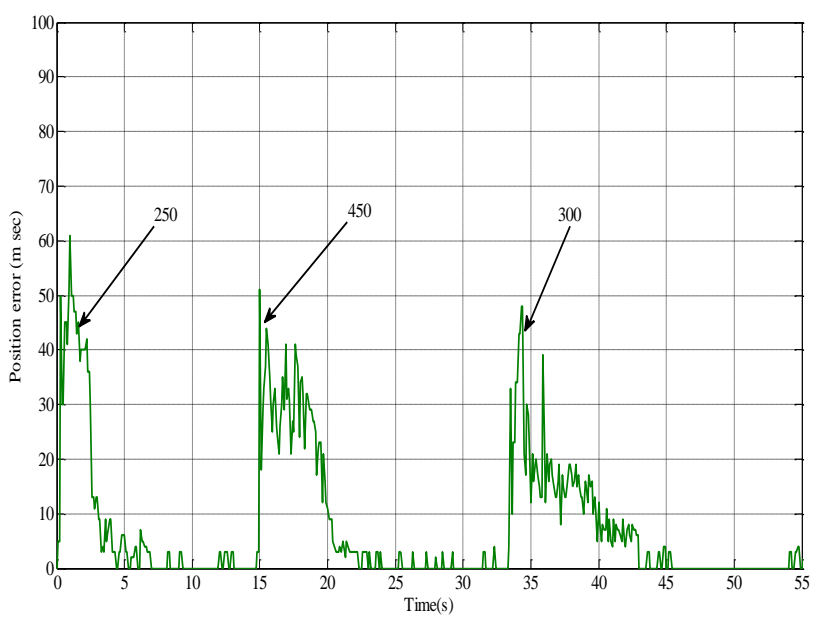

Fig 29: The error angle of master/slave motors when changing the master speed set value

\section{CONCLUSION}

In this research, a detailed study on multi-motor synchronization based on programmable logic controller flexibility has been introduced where the speed and position error of four 3-ph induction motors master/slaves mode of operation are controlled. The performances of the simulated SPWM inverter with constant V/f ratio are improved in controlling the motors speed by using intelligent fuzzy controller. From the practical results, it is note fuzzy controller shows very good tracking to the master-slaves motor with small delay and variation during starting instant and load application. The proposed mechanism of position error correction has good availability in minimize the error between master and slaves motors.

\section{REFERENCES}

[1] Chetan Borse, Akshay Pandhare, and Randhir kumar," PLC Based Induction Motor Starting And Protection", International Journal of Engineering Research and General Science ISSN 2091-2730, Volume 3, Issue 2, March-April, 2015

[2] Chitra.S, Vijaya Raghavan," Conveyor Control Using Programmable Logic Controller", International Journal of Advancements in Research \& Technology ISSN 22787763, Volume 3, Issue 8, August-2014.

[3] Rinchen Geongmit Dorjee," Monitoring and Control of a Variable Frequency Drive Using PLC and SCADA", ISSN: 2321-8169, Volume: 2 Issue: 10, October 2014.

[4] Vismay Chauhan," Multi-motor Synchronization Techniques", International Journal of Science, Engineering and Technology Research (IJSETR), Volume 3, Issue 2, February 2014.

[5] A.A.Thorat1, P.D.Pange2 and V.S.Doijad " speed synchronization of master -slave d.c. motors using Microcontroller, for textile applications" International Journal of Modern Trends in Engineering and Research (IJMTER) Volume 01, Issue 06, e-ISSN: 2349-9745, pISSN: 2393-8161, December, 2014.

[6] Pratiksha Shingade, Arati Dalavi, Priyanka Shipate, Megha Barge" Wireless Digital Control and Synchronization of Master-Slave Multiple Motors Using ARM Microcontroller" Arati Dalavi et al Int. Journal of Engineering Research and Applications ISSN : 22489622, Vol. 4, Issue 5 (Version 2), May 2014, pp.01-02

[7] Azhar Kamel Ajiel," Intelligent Control of Multi ThreePhase Induction Motors", Master of Science Thesis, university of basrah, July 2013.

[8] Moayed N. EL Mobaied " Fuzzy Logic Speed Controllers Using FPGA Technique for Three-Phase Induction Motor Drives" Master of Science Thesis, The Islamic University - Gaza, 2008.

[9] Aumalhuda Gani Abood, Dr. Mohammed A. Jodha and Dr. Majid A. Alwan " A New Hardware Architecture for Fuzzy Logic System Acceleration " Iraq J. Electrical and Electronic Engineering, Vol.12 No.2, 2016. 